\title{
Los retos en investigación, comunicación y educación de los museos de Lima en el marco de la COVID-19. Una discusión sobre los desafíos del futuro a partir de su situación actual y de las experiencias del MALI y el MUCEN
}

\begin{abstract}
The research, communication and education challenges for Lima's
museums in the context of Covid-19. A discussion of the challenges for the future based on their current situation and the experiences of the MALI and MUCEN
\end{abstract}

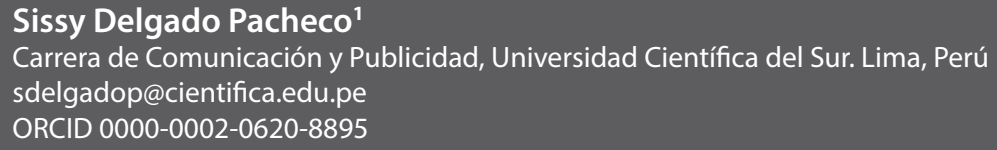

Citar como: Delgado, S. (2020). Los retos en investigación, comunicación y educación de los museos de Lima en el marco de la COVID-19. Una discusión sobre los desafíos del futuro a partir de su situación actual y de las experiencias del MALI y el MUCEN. Desde el Sur, 12(1), pp. 285-306.

\section{RESUMEN}

El 90\% de los aproximadamente 60000 museos que existen en el mundo han cerrado total o parcialmente debido a la COVID-19. En este nuevo contexto uno de los principales retos de los museos es el mantenimiento del compromiso con su público. El estudio busca identificar evidencias que demuestren cuán preparados estaban los museos en la ciudad de Lima para enfrentar un nuevo contexto como la COVID-19 y cuáles son las recomendaciones que podrían seguir en materia de investigación, comunicación y educación.

\footnotetext{
1 Magíster en Administración y Dirección de Empresas por la Universidad de Oviedo (España), y licenciada en Comunicación y Periodismo por la Universidad Peruana de Ciencias Aplicadas (UPC, Perú). Trabaja como responsable académica de la carrera de Comunicación y Publicidad de la Universidad Científica del Sur, donde imparte clases de Principios de Publicidad e Investigación Cualitativa de Públicos y Mercados. Ha publicado el libro El televidentey el uso de las nuevas tecnologías audiovisuales. La experiencia de DIRECTV (Editorial Académica y Española, 2012). Ha seguido estudios en Guadalajara (México), Madrid (España) y Friburgo (Alemania), donde exploró el uso y el impacto de las nuevas tecnologías en la educación, la cultura y el arte. Durante su carrera profesional ha tenido cercanía con el sector museístico, ya que trabajó en la Sociedad Pública de Gestión y Promoción Turística y Cultural del Principado de Asturias (España) y como jefa de Comunicaciones en el Museo de Arte de Lima (MALI).
} 
Para ello, a través de un estudio exploratorio de análisis del discurso se identificó una lista de recomendaciones agrupadas por tres categorías: manejo de colecciones en línea, visitas virtuales y uso de las redes sociales como espacios de aprendizaje. Esta investigación demuestra que los museos que realizaron estrategias relacionadas con las funciones de investigación, comunicación y educación, así como en el uso de tecnologías de información y comunicación, enfrentarán este nuevo contexto con mayores alternativas de distribución de contenidos hacia sus públicos.

Se afirma, entonces, que en este nuevo contexto los museos se convierten en entidades omnipresentes y tienen como reto convertirse en entes vivos, articulados e involucrados con su comunidad digital. Los retos más resaltantes son poner a disposición sus colecciones digitales y acortar las brechas de iniciativas orientadas a la educación. Por último, se identificaron cinco problemas que no permitirán el avance de las recomendaciones señaladas: la falta de estudio de sus públicos, la falta de sostenibilidad financiera, las mínimas estrategias de inclusión, la nueva capacitación de sus colaboradores y la falta de trabajo articulado con otras instituciones.

\section{PALABRAS CLAVE}

Museos, colecciones, programa educativo, redes sociales, tecnologías de la información y comunicación, públicos

\section{ABSTRACT}

Approximately $90 \%$ of the sixty thousand museums that exist around the world have closed either totally or partially due to Covid-19. In this new era, one of the main challenges that museums face is staying connected with their public. This study seeks to identify evidence of how prepared Lima's museums are to face new challenges like that presented by Covid-19, and what recommendations they should follow in terms of research, communication and education.

Following an exploratory discourse analysis based stu$\mathrm{dy}$, a list of recommendations was compiled and grouped into three categories: management of virtual collections, virtual visits, and the use of social networks as learning 
spaces. This research shows that those museums which implement strategies related to their research, communication and educational functions, as well as the use of information and communication technologies, will be in a position to face this new era with greater alternatives for the distribution of content to their public.

In this new era, museums are accessible from anywhere in the whole world, and they must now adapt to a new role as living entities connected to and engaged with their digital community. The most significant challenges will be making their digital collections available online and bridging existing gaps in terms of educational initiatives. Finally, this research identifies five obstacles to implementation of the aforementioned recommendations: lack of market research, lack of financial sustainability, minimal inclusion strategies, the need for new training of museum staff, and the absence of collaboration among institutions.

\section{KEYWORDS}

Museums, collections, educational programs, social media, information and communication technologies, public

\section{Introducción}

El 90\% de los aproximadamente 60000 museos que existen en el mundo han cerrado total o parcialmente debido a la COVID-19 (Unesco, 2020). Más allá del tamaño, la ubicación o la situación, los principales retos que hoy afrontan los museos son la protección de sus colecciones, la garantía de la salud y seguridad de su personal, la resolución de temas financieros y el mantenimiento del compromiso con su público. Esta investigación aborda el último tema, sin dejar de considerar que los otros retos repercuten en la estrategia y la toma de decisión sobre su gestión de públicos.

Antes de la aparición de la COVID-19, los museos competían con los parques y centros comerciales (Kotler y Keller, 2012, pp. 349). El 23 de marzo de 2020 el $20 \%$ de la población global (1,7 billones de personas) se mantenía confinada en sus casas como una medida de control por el virus SARS-CoV-2 (Davidson, 2020). En este nuevo contexto, los museos compiten con otros comportamientos relacionados con el ocio doméstico, como ver la televisión, jugar con la computadora, leer un libro o buscar información en internet. Además de salvaguardar el patrimonio común, hoy deben estar más dedicados a la educación, la inspiración y el diálogo. 
Para los museos emblemáticos del mundo, la reacción del público ha sido más que positiva. A un mes del confinamiento en España, la web del Museo del Prado recibió cerca de 2 millones de visitas virtuales, 258\% más respecto a febrero, y el nivel de interacción de los usuarios en redes sociales superó más de un $190 \%$ que en meses anteriores (Museo del Prado, 2020).

Esta investigación estudia el contexto peruano. Se busca identificar evidencias que demuestren cuán preparados estaban los museos en la capital para enfrentar un nuevo contexto como la COVID-19 y cuáles son las recomendaciones que podrían seguir en materia de investigación, comunicación y educación.

\section{Metodología}

A través de un estudio exploratorio y cualitativo de análisis del discurso, se construyó un listado de recomendaciones agrupados en las categorías «Manejo de colecciones», «Visitas virtuales» $y$ «Uso de redes sociales para espacios de aprendizaje», alineado a las funciones esenciales de los museos de investigación, comunicación y educación. Seguido a ello, se presenta un diagnóstico general de los museos de Lima para identificar cuán preparados se encontraban para enfrentar un nuevo contexto como la COVID-19. Se eligió por conveniencia dos museos que cuentan con colecciones en línea disponibles al público y que han trabajado contenidos digitales como visitas virtuales, aplicaciones móviles, podcasts, videos, entre otros. Mediante entrevistas en profundidad a responsables del Museo de Arte de Lima (MALI) y del Museo Central (MUCEN), se analizó el trabajo previo que han podido desempeñar y sus proyectos futuros. Finalmente, se discuten oportunidades y limitaciones en el desenvolvimiento del sector, así como los principales retos hacia el Bicentenario.

\section{Sobre el Museo de Arte de Lima (MALI)}

Inaugurado en 1959 por el Patronato de las Artes e instituido en el Palacio de la Exposición, el MALI es uno de los museos más representativos de América Latina. A partir de una política activa de adquisiciones de obras y donaciones, se ha convertido en la primera pinacoteca del país y en la mayor colección artística en el Perú que narra 3000 años de historia del arte peruano. Se trata de una institución privada sin fines de lucro, cuya última gran obra fue la apertura de la exposición permanente en el segundo piso en 2015. Con ocasión de los 60 años de la fundación del MALI, en 2014, se lanzó su colección virtual abierta al público para dar acceso a las colecciones del museo. Los cursos y talleres artísticos del MALI equivalen al $50 \%$ de su fuente de recaudación. 


\section{Sobre el Museo Central (MUCEN)}

Inaugurado en 1982 y renombrado como Museo Central (MUCEN), tiene como misión ayudar a fortalecer a la ciudadanía mediante el conocimiento y la valoración de nuestra diversidad cultural. A diferencia de otros centros expositivos que unen esfuerzos en mostrar y enriquecer sus colecciones, su principal estrategia es fortalecer su curaduría pedagógica. La naturaleza del MUCEN es distinta. Se trata de un museo del Estado que depende del Banco Central de Reserva, un organismo público independiente que no responde a ningún ministerio. El MUCEN, por tanto, cuenta con cierta independencia, pero mantiene contacto con el Ministerio de Cultura para responder a las normativas de Ley de Patrimonio y alinearse a programas como el de Museos Abiertos (MUA).

\section{El concepto de museo y sus funciones esenciales}

La Organización de las Naciones Unidas para la Educación, la Ciencia y la Cultura (Unesco) se ha encargado de concebir y promover el museo como una institución destinada a reforzar la educación y la convivencia en sociedad. Gestado desde la década de 1960, a este modelo museológico se le ha denominado «nueva museología» (De Carli, 2004, p. 59). Es a partir de este modelo que, en la Recomendación relativa a la protección y promoción de los museos, su diversidad y su función en la sociedad publicada por la Unesco en 2015, la misión de los museos es la siguiente: «una institución permanente, sin fines lucrativos, al servicio de la sociedad y de su desarrollo, abierta al público, que adquiere, conserva, investiga, comunica y expone el patrimonio material e inmaterial de la humanidad y su medio ambiente con fines de educación, estudio y recreo» (Unesco, 2015, p. 27).

De las funciones esenciales proclamadas por la Unesco (2015), las tres últimas tienen una conexión de cara al público y serán materia de estudio.

a. Preservación: actividades relacionadas con la adquisición y gestión de colecciones, así como la seguridad, la conservación preventiva y correctiva, y la restauración de piezas en exhibición y almacenadas.

b. Investigación: estudio de las colecciones para reflexionar sobre la historia en un contexto contemporáneo e interpretar y exponer las colecciones (AAM, 2020c).

c. Comunicación: difusión activa de conocimientos sobre las colecciones, los monumentos y los sitios. Incluye los actos públicos y actividades culturales en forma física y digital (Mariátegui, 2020; Riaño, 2020; Kotler, 2011).

d. Educación: los museos imparten educación formal y no formal, a través de la elaboración y transmisión de conocimientos y programas educativos y pedagógicos con otras instituciones, especialmente la escuela (Alemán, 2017). 
Es importante mencionar que a partir de 2015 — cinco años antes del nuevo contexto del COVID-19 - la Unesco insta a las autoridades de las instituciones museísticas a ser conscientes de que las tecnologías de la información y la comunicación (TIC) son una oportunidad para las funciones mencionadas.

La última Guía de museos del Perú, publicada por el Ministerio de Cultura en 2012, afirma que los museos se conciben como una herramienta educativa y de entretenimiento en la población peruana. Son espacios abiertos a todo público y ayudan a enlazarnos con nuestro pasado y presente $^{2}$. Desde 2012, el Ministerio de Cultura reconoce la importancia de mantener las tradiciones peruanas en un mundo globalizado y permitir «el surgimiento de museos comunitarios, locales, de sitio, ecomuseos, virtuales y otros» (Ministerio de Cultura 2012, p. 18). Así, se evidencia que el interés en las nuevas tecnologías para la innovación y en la creación de museos virtuales ya estaban vigentes al menos cinco años previos antes del nuevo contexto de la COVID-19.

\section{COVID-19: replanteamiento en la investigación, la comunicación, la educación y el uso de nuevas tecnologías}

Las principales instituciones del sector recomiendan cómo potenciar su comunicación virtual con sus públicos durante la cuarentena (AAM, 2020a; AAM, 2020b; AAM, 2020c; ICOM, 2020; Riaño, 2020). A partir de la información recogida y alineadas a las funciones esenciales de los museos en investigación, comunicación y educación, se presentan las recomendaciones para mostrar las colecciones en línea y proponer estrategias creativas que mantengan al público entretenido, inspirado y relajado de la ansiedad que produce el confinamiento:

2 Bajo la normativa en el Perú, a través del Decreto Ley 27590, se crea el Sistema Nacional de Museos del Estado en 1992 para establecer la conservación y exhibición del patrimonio cultural mueble del país. Los museos en el Perú se dividen en museos estatales (nacionales, regionales, municipales, comunitarios o de sitio) y museos privados (organizaciones particulares, fundaciones, sociedades, asociaciones e instituciones religiosas y educativas). Por la naturaleza de sus colecciones, los museos pueden ser arqueológicos, históricos, de ciencias naturales, etnográficos, artísticos, religiosos, tecnológicos, de arte popular y museos especializados por temas, como la Casa de Literatura o la Casa de la Gastronomía Peruana, entre otros. En la actualidad, no existe a disposición del público un registro minucioso de la cantidad de museos en el Perú. 


\begin{tabular}{|c|c|c|c|c|c|c|}
\hline 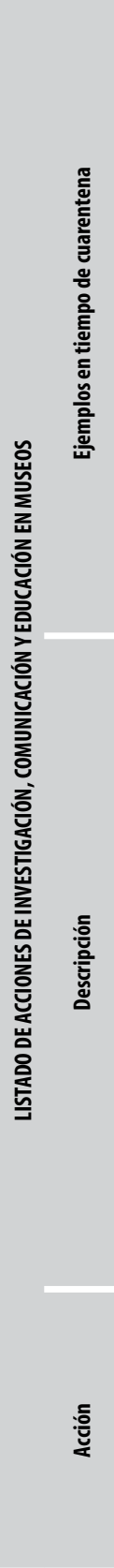 & 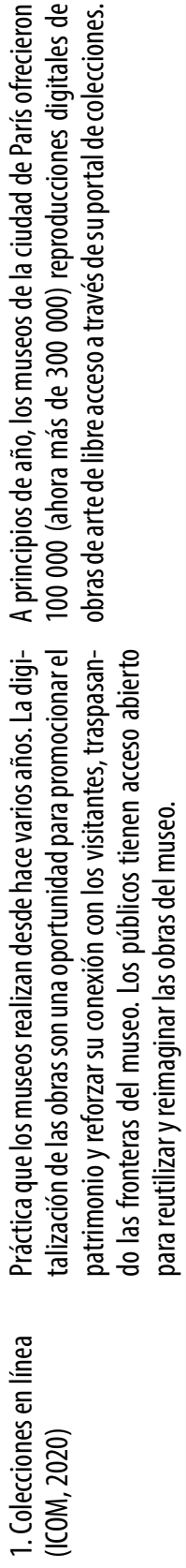 & 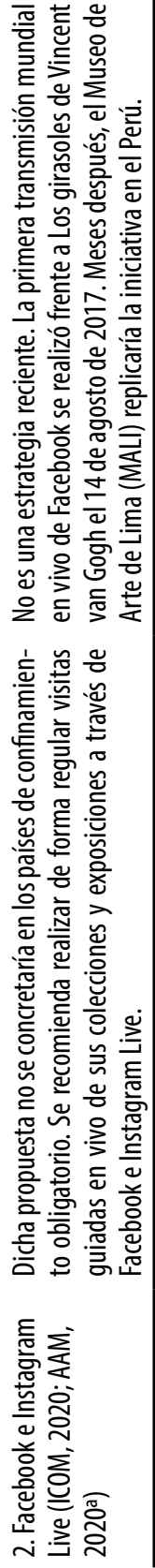 & 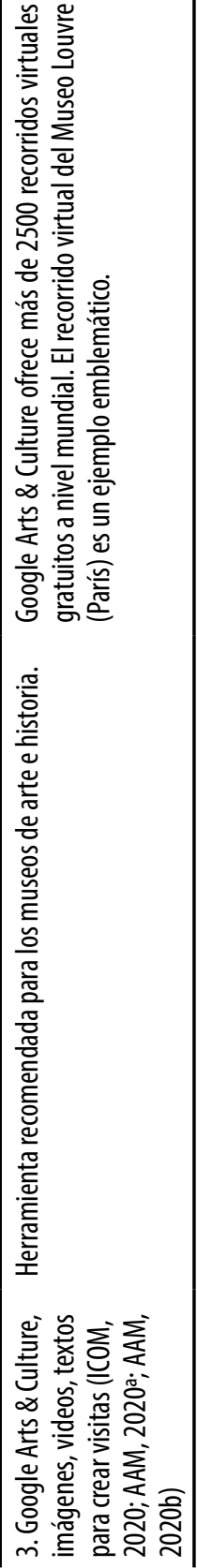 & 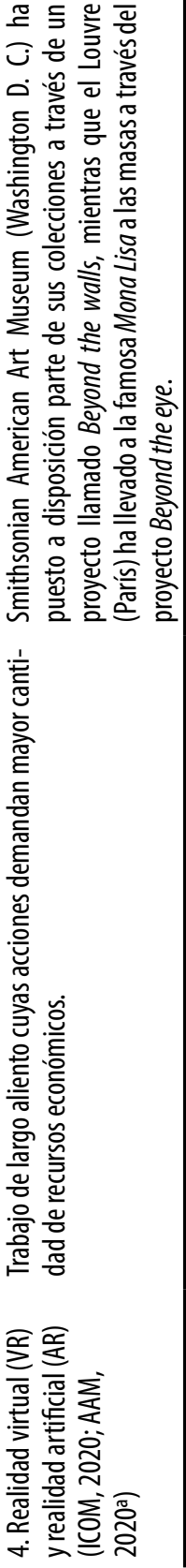 & 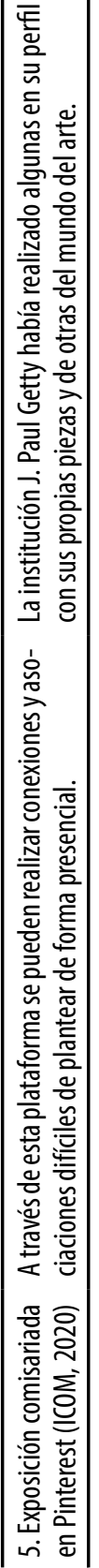 & 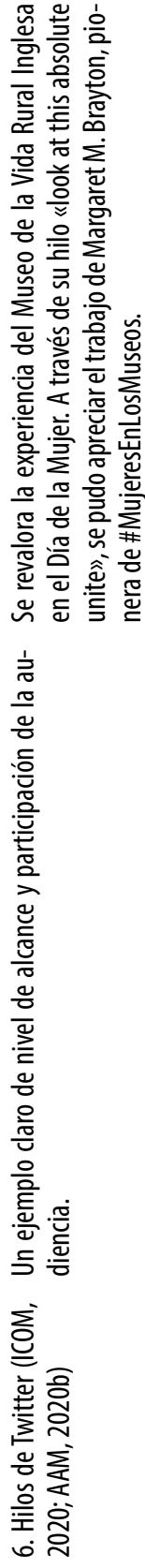 \\
\hline 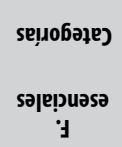 & $\begin{array}{l}\text { SJNOIJ) } \\
\text { IO OFINHWW }\end{array}$ & \multicolumn{5}{|c|}{ 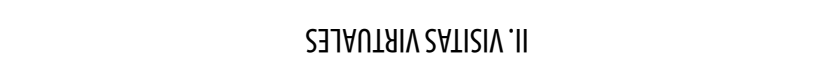 } \\
\hline
\end{tabular}




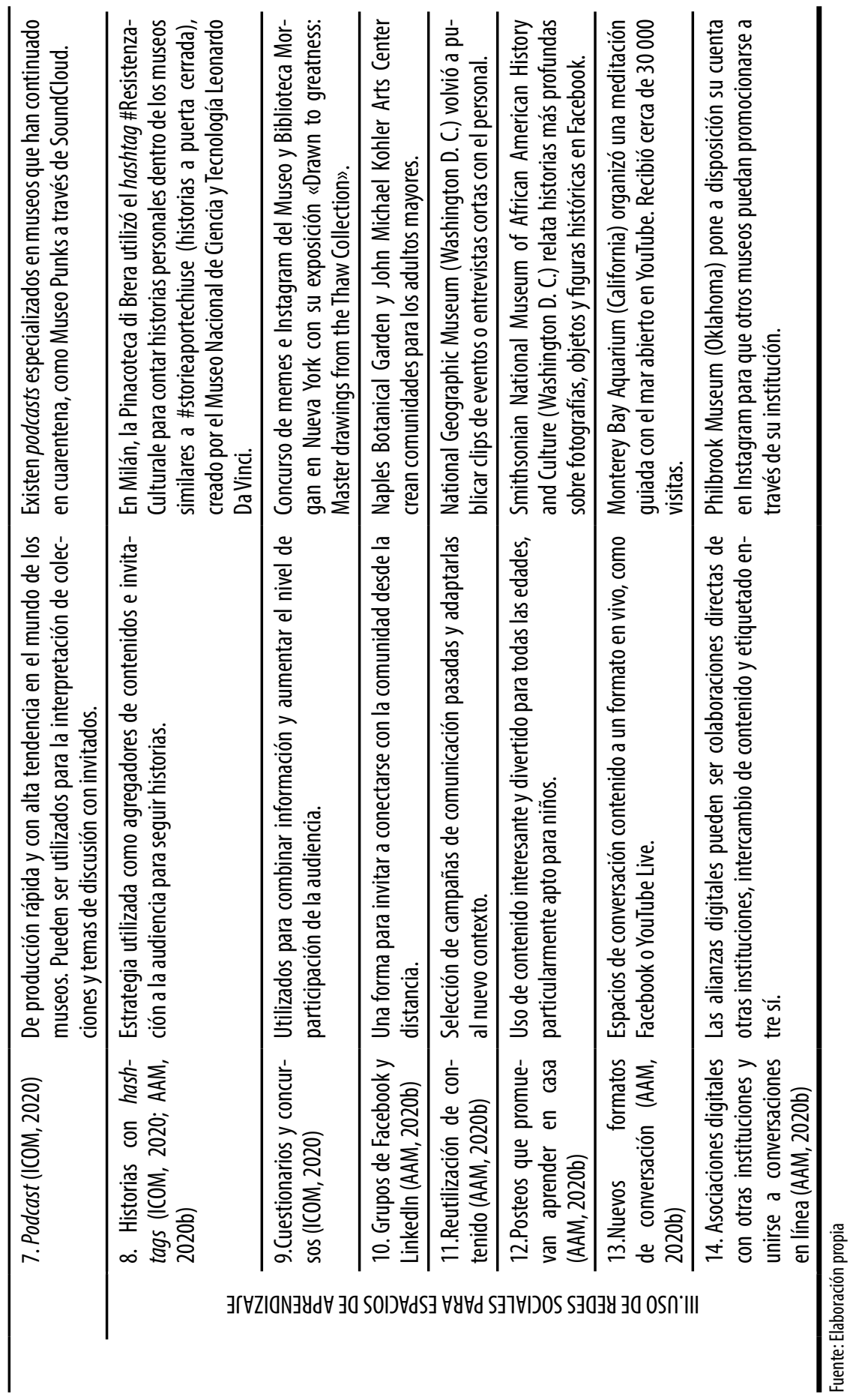




\section{Discusión sobre la situación de los museos en el país, a partir del diagnóstico general en materia de investigación, educación y comunicación, y los casos MALI y MUCEN}

En el contexto de la COVID-19, urge la transformación de los museos hacia un modelo virtual y accesible. Un museo será más accesible a medida que comparta libremente sus colecciones, investigaciones y programas educativos a través de sus páginas web y redes sociales (Riofrío, 2019). A continuación, se realizará un diagnóstico sobre la situación de los museos en Lima a partir de las investigaciones de Alvarado (2018) y Riofrío et al. (2019), siguiendo el lineamiento de las funciones esenciales de los museos (Unesco, 2015), las recomendaciones identificadas por parte de organizaciones internacionales del sector (AAM, 2020a; AAM, 2020b; AAM, 2020c; ICOM, 2020) y destacando las acciones que han realizado el MALI y el MUCEN, que han sido recogidas de sus páginas web, redes sociales, y mediante entrevistas a profundidad realizadas a Patricia Villanueva (curadora educativa del MALI) y María Pilar Riofrío (directora del MUCEN). EI MALI y el MUCEN exhiben sus colecciones online y son de los pocos museos que destacan en el sector (Mariátegui, 2020).

Es resaltante que los trabajos encontrados sobre museos en el Perú ${ }^{3}$ parten, en su mayoría, de un estudio sobre la oferta y la demanda (Alvarado, 2018) y una agenda de sostenibilidad en el sector de museos (Riofrío et al., 2019), publicaciones que son parte del Diseño de estrategias para mejorar la autosostenibilidad de los museos y centros expositivos de Lima (Proyecto Innóvate), que tuvo como objetivo — de 2016 a 2019- construir una ruta hacia museos más sostenibles. Cabe destacar que no se han encontrado otros estudios cuantitativos similares anteriores.

En cuanto a la función esencial de la investigación (Unesco, 2015), que responde a la categoría «Manejo de colecciones en línea» (I), se sabe que en Lima el $72 \%$ de museos ha digitalizado su colección con registro fotográfico (Alvarado, 2018). Sin embargo, solo el $41 \%$ de museos cuenta con un sistema digital de manejo de colecciones (Riofrío, 2019). Por tanto, menos de la mitad de los museos tiene registro de su patrimonio cultural a disposición del público.

En el caso del MALI, el interés de colocar sus colecciones en línea (2014) surgió a partir del proyecto de apertura de la exposición permanente del museo en 2015. Meses después, se lanzó una aplicación móvil con

3 La muestra final del estudio consistió en 87 organizaciones, de las cuales 50 eran museos y 37 centros expositivos. La metodología de muestreo inicial fue aleatoria, a través de una clasificación basada en el listado de organizaciones, lo cual permitió la recolección de datos representativos del universo. 
audioguías (2016) para complementar las visitas (Delgado, 2020b). Sumado a ello, el MALI maneja el proyecto Archivo Digital de Arte Peruano (ARCHI) (http://archi.pe), una plataforma publicada en 2016, donde se documenta y difunde el patrimonio cultural en el Perú y de la que se detallará más adelante. Por otro lado, el Sistema Digital de Colecciones del MUCEN fue lanzada a mediados de febrero de este año tras un trabajo de registro y producción de tres años (Delgado, 2020a).

Por otro lado, el $68 \%$ de museos brinda servicios especializados a investigadores en el acceso a sus colecciones para fomentar el estudio, el análisis y las publicaciones. Dicha información es la base para los contenidos del museo, las exposiciones temporales y los materiales educativos (Alvarado, 2018). En el caso del MUCEN y el MALI se debe mencionar que ambas instituciones últimamente han trabajado con curadores e investigadores externos (Delgado, 2020a; Delgado 2020b) para proyectos y exposiciones temporales.

Estos hallazgos instan a los museos a reforzar su trabajo e interés en la investigación a través de sus colecciones en línea, ya que los museos dejan de ser espacios presenciales para convertirse en las nuevas enciclopedias (Mariátegui, 2020). Sus colecciones en línea serán la fortaleza de la institución y la base para las siguientes recomendaciones ante el nuevo contexto.

Según la Unesco (2015), los museos deben comportarse como un reflejo de la sociedad y ofrecer a sus visitantes otras visiones del mundo, fomentando así la creatividad, la imaginación y el respeto de sí mismo y de los demás. Ante ello, son instituciones donde la sociedad debe verse reflejada y pueda responder las preguntas: ¿quiénes somos? ¿De dónde venimos? ¿Hacia dónde vamos? En Lima, el 73\% de los museos grandes albergan colecciones de arte, mientras que ningún museo grande cuenta con colecciones de etnografía y antropología (Alvarado, 2018). Históricamente, se ha otorgado un mayor valor a las expresiones artísticas y contemporáneas debido a que responden a intereses de coleccionistas privados y del mercado del arte. Si bien es posible realizar interpretaciones de historia y sociedad a través de piezas artísticas, es importante reconocer que los museos más grandes en Lima están reservados para la apreciación del arte. En este nuevo contexto, los museos medianos y pequeños, como la Casa de la Literatura o la Casa de la Gastronomía, deberán aprovechar la oportunidad de estimular el diálogo sobre temas como la inequidad social y otros problemas contemporáneos a través de sus colecciones (AAM, 2020c).

A ello, se suma la necesidad de implementar estrategias que reafirmen la identidad multicultural en el Perú y que generen conexiones y 
reflexiones para reconocer y valorar la riqueza en estas diferencias culturales. La Primera Encuesta Nacional de Percepciones sobre Diversidad Cultural y Discriminación Étnico-Racial (Ministerio de Cultura, 2018, citado por MUCEN, 2018, p. 15) contiene afirmaciones como «solo el 50\% de los encuestados conoce en cierta medida el término diversidad cultural; el $42 \%$ piensa que sería mejor que en el Perú todos hablaran una única lengua (español); y solo el $8 \%$ se autoidentifica como racista, pero $53 \%$ de los peruanos considera que otros sí lo son».

Las categorías «Visitas virtuales» (II) y «Uso de redes sociales para espacios de aprendizaje» (III) responden a las funciones esenciales de comunicación y educación (Unesco, 2015) y parten de una estrategia más amplia, que es la de contar con una campaña consistente de comunicación, la que a su vez se deriva de una estrategia de marketing. El marketing cultural cumple con el objetivo de poner en contacto lo que se ofrece a los consumidores y alcanzar los objetivos alineados a la misión de la organización cultural (Colbert y Cuadrado, 2003). En ese sentido, los empleados de un museo deben conocer su misión y sus objetivos. Llama la atención que, en Lima, el 58\% de museos y centros expositivos no ha formulado su misión o visión, no las conocen o no las recuerdan (Alvarado, 2018). Ello evidencia una falta de visión y estrategia a futuro, y podría ser uno de los problemas que están enfrentando en este nuevo contexto.

Los canales de comunicación utilizados entre los museos y sus públicos ya eran digitales. El $72 \%$ cuenta con página web. El $82 \%$ indica que Facebook es el medio favorito y efectivo debido a su fácil uso, barato e impacto deseado, directo y rápido con su público. Por otro lado, el $47 \%$ del público entrevistado ha escuchado de los museos a través de páginas web y redes sociales (Alvarado, 2018). El MALI fue uno de los museos pioneros en el Perú en el uso de las redes sociales. Su página en Facebook fue lanzada en 2008 y, después de la Casa de la Literatura, es la institución cultural con la mayor cantidad de seguidores (cerca de 350 000) en esta red social (https://www.facebook.com/museodeartedelima/).

A pesar de estas evidencias, no podemos considerar al sector como digitalizado, ya que existen pocas iniciativas con aplicaciones móviles (Riofrío et al., 2019). Por ejemplo, solo el 7\% de los museos -entre ellos el MALI - ofrece servicio de audioguías o aplicaciones móviles (Alvarado, 2018). Desde el sector público es importante comentar que, a partir de agosto de 2019, 12 museos de los 50 que administra el Ministerio de Cultura pueden ser visitados de forma virtual a través de la página web (https://visitavirtual.cultura.pe/). Asimismo, los visitantes pueden complementar su visita a través de fotografías y modelos 3D de algunas piezas y guías de audio (Ibermuseos, 2019). A mayo de 2020 el número de sitios 
ascendió a 23 y la página alcanza casi un millón de visitas (Ministerio de Cultura, 2020). A pesar de dichos esfuerzos, solo se pueden visitar virtualmente casi el $50 \%$ de los museos administrados por el Ministerio de Cultura.

En cuanto a las «Visitas virtuales» (II), antes del nuevo contexto de la COVID-19 el 70\% de los museos ofrecía servicios de guiado tradicional, pero no contaban con programas educativos basados en el diálogo, la interactividad y la mediación cultural (Riofrío et al., 2019). Por el contrario, desde las necesidades de la oferta, los visitantes sí están interesados en que los museos sean espacios más sociales para vivir más experiencias. Es decir, pedían que sean más participativos e interactivos (Alvarado, 2018). En el caso del MUCEN, desde 2016 ha buscado un reposicionamiento como museo, que lo diferencia de la oferta brindando experiencias, sensaciones y conexiones personales del público como introducir música, performances y susurro de versos en sus salas de exposición (Delgado, 2020a).

Si bien las visitas virtuales a través de Facebook e Instagram Live (2) no han sido posibles durante la pandemia, es importante resaltar que el MALI tuvo como iniciativa, en el marco del mes de los museos, su proyecto \#MALIENVIVO, de mayo a diciembre de 2018 , donde todos los jueves un curador o especialista del museo comentaba, vía Facebook Live e Instagram Live, una pieza, sala o exposición temporal, además de las actividades de la curaduría educativa, áreas de restauración y biblioteca (https:// www.facebook.com/museodeartedelima/). Este tipo de acciones podrían realizarse en caso los futuros protocolos de bioseguridad lo permitan.

Cabe destacar que la recomendación "Colocar las colecciones en línea» (1) impacta en "Visitas virtuales a través de Google Arts \& Culture, imágenes, videos, textos para crear visitas» (3). En 2012 el MALI emprendió el proyecto Google Art Project (hoy llamado Google Arts \& Culture), donde puso a disposición más de 300 imágenes. El MALI compartió dicho proyecto con otros museos como The Metropolitan Museum of Art (MET) y el Museum of Modern Art (MoMA) en Nueva York, y el Tate Britain de Londres (MALI, 2012). A la fecha, existen 10 colecciones de museos peruanos dentro de la plataforma: Museo Mario Testino (MATE), Museo de Arte Contemporáneo (MAC), Museo Machu Picchu, Museo Larco, entre otros (Google Arts \& Culture, 2020). El MUCEN, que no se encuentra en dicha plataforma, ofrece cuatro recorridos virtuales a través de fotografías 3D (2017), cuya principal intención fue registrar las exposiciones temporales. Sin embargo, nunca trabajó el recorrido virtual de la exposición permanente en este formato (Delgado, 2020a). En el MUCEN se evidencia un especial interés en el registro y la promoción de sus exposiciones temporales. 
La recomendación «Uso de realidad virtual (VR) y realidad artificial (AR)» (4), que es la que demanda mayores recursos tecnológicos, no se ha podido realizar en ninguna de las instituciones para este contexto, pero vale resaltar el uso de la realidad virtual desarrollada por el MALI para la exposición temporal Nasca en 2017. Fly Nasca fue un simulador en 3D que permitió a los visitantes sobrevolar y conocer los geoglifos de Nasca y Palpa. Dicha experiencia fue promocionada en redes sociales con el hashtag \#NascaDigital (https://www.facebook.com/museodeartedelima/). Como las visitas virtuales del MUCEN, esta también evidencia el esfuerzo de los museos en buscar herramientas de promoción para sus exposiciones temporales.

A diferencia de otros países como Estados Unidos, el uso del podcast (recomendación 7) no está tan extendido en el Perú. Según el estudio de la empresa Redmas (2019), del $60 \%$ de internautas que consume actualmente audio digital, solo el $20 \%$ escucha podcasts (Cóndor, 2019). En abril de 2020 el MUCEN presentó su proyecto MUCEN Literario, a través de 14 videos en formato podcast (con un solo narrador), que profundiza en una selección de obras de arte del MUCEN relacionadas con el mundo literario (https://www.facebook.com/MUCENmuseocentral/). Del mismo modo, el MALI cuenta con el proyecto \#ExploraMALI, una serie de videos en formato podcast (con un solo narrador) sobre temas precolombinos, investigados y narrados por sus curadores. Llama la atención que la conversación, titulada Museos de Arte en tiempo de coronavirus, entre su exdirector Bartomeu Marí y Nicolás Gómez, director del MAC Lima, fue publicada el 2 de abril en la página de Facebook del MALI como un texto escrito en formato PDF (https://www.facebook.com/museodeartedelima/). Grabar dicha conversación como podcast pudo haber sido una gran oportunidad de innovación en el sector.

El grupo de recomendaciones «Uso de redes sociales para espacios de aprendizaje» (III) está estrechamente relacionado con el trabajo previo de las curadurías educativas de las instituciones, ya que, si bien las redes sociales son el canal facilitador de información, el contenido proviene del trabajo de interpretación previa. En ese sentido, solo el $30 \%$ de los museos en Lima cuenta con programas educativos (Alvarado, 2018). Esta cifra es baja si se compara con el $89 \%$ de los museos que brinda recorridos guiados. Resulta evidente que antes del contexto de la COVID-19 el principal servicio había sido escuchar a un guía o mediador, y no usar metodologías de aprendizaje. Otro punto que destacar es que el $60 \%$ de los museos ya ofrecía servicios de dictado de cursos y talleres para público general, mientras que el $64 \%$ de los museos organizaba conferencias, encuentros y conversatorios (Alvarado, 2018). Será más fácil para los museos 
que cuentan con una programación de actividades y el compromiso de sus exponentes y participantes continuar sus actividades bajo este nuevo contexto. El reto será invertir recursos en la interpretación de su colección para fomentar el aprendizaje.

Las recomendaciones «Contar historias con hashtags» (8), «Reutilización de contenido» (11) y «Posteos que promuevan aprender en casa» (12) han sido más rápidos de resolver para el MALI y el MUCEN, debido a que sí ofrecen programas educativos $y$, por tanto, tienen material dirigido a la enseñanza. Del grupo que ofrece programas educativos, el 53\% entrega recursos a los profesores en sala, el 33\% por correo electrónico y el $27 \%$ podían ser descargados en la web (Alvarado, 2018). En el nuevo contexto, los museos aún deben fortalecer la distribución digital de sus contenidos educativos.

EI MALI cuenta como libro base la Guía MALI (2015) —hoy disponible en digital-, publicación que contiene el nuevo guion museográfico de las salas de exposición permanente, con una introducción a la historia del museo y el desarrollo de secciones dedicadas al arte precolombino hasta el moderno. Además, el MALI quiso poner énfasis en la experiencia museal y consideró que era importante implementar un programa educativo. Con la creación de la posición de una curadora educativa (2015), se establecen tres ejes temáticos transversales (identidad, entorno y conservación), de manera que cada uno de los programas está articulado para cada nivel educativo, con todas las currículas y todos los temas, desde cultura, geografía hasta matemática y educación física (Delgado, 2020b).

Por otro lado, dentro de la plataforma del Archivo Digital de Arte Peruano se lanzó Archi para aprender (2020), un repositorio de materiales de apoyo para el docente y sus estudiantes con el contenido educativo de las exposiciones realizadas por el MALI y la Fundación Telefonica de 2005 a 2008. Este proyecto incluye también trivias, juegos y rompecabezas (Delgado, 2020b). Ante lo expuesto, la recomendación «Cuestionarios y concursos» (9) ha sido resuelta por parte de este museo, dentro de una campaña de comunicación que tiene como hashtag \#MALlenCasa.

La estrategia del MUCEN durante la cuarentena fue recurrir a su publicación Conexiones (2019) —aún no disponible en digital-, una lectura contemporánea de obras de arte. Por otro lado, guiones de exposiciones temporales anteriores se convertirán también en insumos de próximas publicaciones. Por otro lado, en 2018 sus mediadores desarrollaron nueve fichas pedagógicas de previsita dirigidas a docentes, que servían para que estos preparen y motiven a sus alumnos antes de visitar el museo, así como para generar conexiones con las competencias indicadas en el currículo escolar. Asimismo, han reutilizado un proyecto anterior de arte 
contemporáneo para presentar \#UnaObraMucenPorDía y continuarán realizando otras campañas (Delgado, 2020a).

Así como se ha realizado un análisis de las recomendaciones en torno a la COVID-19 dadas por las instituciones internacionales del sector (AAM, 2020a; AAM, 2020b; AAM, 2020c; ICOM, 2020; Riaño, 2020), es importante mencionar cinco problemas que atañen a los museos, que — si no son replanteados o resueltos - no permitirán el avance de las recomendaciones señaladas ante el nuevo contexto al que se enfrentan. Estos son la falta de estudio de sus públicos, la falta de sostenibilidad financiera, las mínimas estrategias de inclusión, la nueva capacitación de sus colaboradores y la falta de trabajo articulado con otras instituciones (Alvarado, 2018; Riofrío et al., 2019; Holmquist, 2020). Y estos son los retos que deberán enfrentar también aquellos museos cuyas inauguraciones se deberían realizar a puertas del Bicentenario: el Museo Nacional (MUNA), el Museo Nacional de Arqueología, Antropología e Historia del Perú, y el Museo Brüning de Lambayeque.

En el campo de la investigación de públicos solo el $16 \%$ de organizaciones ha realizado un estudio de visitantes, equivalentes a tres centros culturales, dos galerías y nueve museos. Además, en cuanto al involucramiento con el público, es importante contar con programas de fidelización. En el Perú son escasos. Solo cuatro museos cuentan con programas de voluntariados (Alvarado, 2018). Por tanto, podemos afirmar que el sector de museos «se encuentra divorciado de su público en gran medida, por lo que los programas, proyectos y eventos que desarrollan los museos y centros expositivos se realizan sin contar con las necesidades, opiniones e intereses del público y de su comunidad circundante» (Riofrío et al., 2019).

Si bien el $43 \%$ de museos y centros expositivos ha realizado mejoras de accesibilidad en su infraestructura, el 95\% no ha realizado ningún avance en la adaptación de sus contenidos museográficos para personas con discapacidad visual y auditiva (Alvarado, 2018). Desde setiembre de 2019 el MUCEN ha ofrecido cuatro recorridos dirigidos a la comunidad de sordos. Como parte de la digitalización de los programas educativos se buscará incluir el lenguaje de señas en cada video (Delgado, 2020b). No resulta casual que el tema establecido globalmente en el Día Internacional de los Museos sea «Museos por la igualdad: diversidad e inclusión», y haya alentado el desarrollo de mesas redondas y talleres virtuales para hablar de las problemáticas actuales, principalmente en el nuevo contexto de la COVID-19 (https://www.facebook.com/mincu.pe/).

Si los museos ya pasaban por problemas financieros que han impedido su autosostenibilidad, aún necesitan fortalecer su planificación 
estratégica y financiera, diversificar sus ingresos y generar ingresos propios (Riofrío et al., 2019), especialmente los que administra el Ministerio de Cultura, debido a que alrededor del $60 \%$ del presupuesto proviene de entradas de museos, monumentos, Machu Picchu, Camino Inca, etc. (Museos 2020, 2020).

Otra de las preocupaciones es el vacío profesional y de redes de colaboración entre los profesionales de museos, ya que sus conocimientos no han sido potenciados por parte de las escuelas, programas universitarios o de formación técnica (Holmquist, 2020). Es importante mencionar que, desde 2017, el British Council ha organizado el programa Transformando Museos para el Futuro, iniciativa global conocida en otros países como International Museums Academy. A través de conferencias y talleres ha contribuido en la mejora de gestión de colecciones, programas públicos y educativos, y estrategias para la equidad, diversidad e inclusión, así como la sostenibilidad de los museos, innovación y tecnología digital (British Council, 2020). Pero ahora el reto es mayor. A falta de recursos, hoy los curadores realizan labores de investigación, escritura de guiones y otras actividades de comunicación, como edición de video (Delgado, 2020b). Si bien ha sido tomado como una experiencia positiva y renovadora, las instituciones encargadas de monitorear y velar por el bienestar del sector deben replantear nuevos tipos de capacitaciones que conviertan a los curadores en creadores y ejecutores de sus propias piezas de comunicación.

Pese a que existen en el Perú el Sistema Nacional de Museos del Estado y la Oficina del Consejo Internacional de Museos (ICOM, por sus siglas en inglés), así como redes culturales privadas como la Red de Museos del Centro Histórico de Lima, la Red de Pedagogía de Museos, la Asociación de Curadores del Perú, la Asociación Nacional de Museólogos del Perú o la Red de Museos de Barranco, aún no ha sido creada una red que integre a todos los museos de Lima (Riofrío et al., 2019). Por tanto, existe un bajo nivel de coordinación y cohesión en el sector, cuya consolidación requerirá tiempo, recursos y liderazgo. El contexto de la COVID-19 es una oportunidad para establecer alianzas estratégicas, buscar objetivos comunes para crear comunidad y descubrir formas de innovación.

De esta manera, las recomendaciones sobre la creación de «Exposición comisariada en Pinterest» (5), «Grupos de Facebook y Linkedln» (10), «Nuevos formatos de conversación» (13) y «Asociaciones digitales con otras instituciones y unirse a conversaciones en línea» (14) se implementarán a medida que los museos inicien el desarrollo de estrategias de trabajo conjunto y se convertirán en evidencia como parte de las iniciativas en el nuevo contexto. 


\section{Conclusiones}

- El contexto de la COVID-19 se ha convertido en una oportunidad para los museos, ya que hoy están obligados a tomar decisiones que en una situación de normalidad no hubiesen tenido el valor de implementar, debido a su especial interés en su experiencia presencial. El compromiso digital provocado por la cuarentena de la COVID-19 no será efímero, sino se mantendrá durante la nueva normalidad. Ante este escenario no esperado por el sector, los museos se ven forzados a inventar, retomar y reforzar sus estrategias digitales.

- Existe evidencia que muestra el trabajo previo de virtualización de colecciones y conexión con el público a través de canales digitales. Aquellos museos o instituciones que tuvieron un interés especial en las funciones esenciales de investigación, comunicación y educación, y en el uso de tecnologías de información y comunicación, enfrentan la crisis con mejores y mayores alternativas de distribución de contenidos, manejo de públicos y conexión con sus audiencias, más allá de su situación de financiamiento. Por un lado, reaprovecharán los recursos digitales y contenidos utilizados anteriormente, y, por otro, crearán nuevas campañas de comunicación dirigida a las necesidades reales de su público, especialmente relacionados con la educación.

- Alineadas a estas funciones, se han determinado las siguientes recomendaciones divididas en tres categorías: I) «Manejo de colecciones en línea»: «Colecciones en línea», 1; II) «Visitas virtuales»: «Facebook e Instagram Live», 2, «Google Arts \& Culture, imágenes, videos, textos para crear visitas», 3; «Realidad virtual (VR) y realidad artificial (AR)», 4; «Exposición comisariada en Pinterest», 5; «Hilos de Twitter», 6; «Podcast», 7; III) «Uso de redes sociales para espacios de aprendizaje»: «Historias con hashtags», 8; «Cuestionarios y concursos», 9; «Grupos de Facebook y Linkedln», 10; «Reutilización de contenido», 11; «Posteos que promuevan aprender en casa», 12; «Nuevos formatos de conversación», 13; $y$ «Asociaciones digitales con otras instituciones y unirse a conversaciones en línea», 14.

- En cuanto a la investigación y comunicación, si bien los canales de comunicación utilizados entre los museos y sus públicos ya eran digitales, no podemos decir que el sector está digitalizado, ya que del $72 \%$ de los museos que ha digitalizado su colección, solo el $41 \%$ cuenta con un sistema digital abierto a sus públicos. Además, existen pocas iniciativas con aplicaciones móviles. Solo el $7 \%$ de los museos cuentan con aplicaciones móviles (Alvarado, 2018).

- Una problemática resaltante es el avance desigual en iniciativas orientadas a la educación. Solo el $30 \%$ de los museos cuentan con programas educativos. Por otro lado, el $89 \%$ de los museos brinda recorridos guiados (Alvarado, 2018). Antes del contexto de la COVID-19, el principal servicio había sido escuchar a un guía o mediador, y no usar metodologías de aprendizaje. Ello podría ser una dificultad para el 
trabajo dentro de la institución y un posible articulado con el programa Aprendo en casa, educación pública virtual inicial, primaria y secundaria que se brinda durante la pandemia.

- El trabajo en curaduría educativa en el MALI y el MUCEN proviene de un esfuerzo sostenido y avalado por la institución. En el MALI la necesidad de una curaduría educativa surgió con la creación de la exposición permanente en 2015. Por su parte, el MUCEN, desde 2016, ha buscado un reposicionamiento como museo, que lo diferencia de la oferta al brindar experiencias, sensaciones y conexiones personales del público. Ambos están alineados temporalmente a la Recomendación relativa a la protección y promoción de los museos, su diversidad y su función en la sociedad publicada por la Unesco en 2015.

- Además de las recomendaciones en torno a la COVID-19, se han identificado cinco problemas que atañen a los museos, que, si no son replanteados o resueltos, no permitirán el avance de las recomendaciones señaladas. Estos son la falta de estudio de sus públicos, la falta de sostenibilidad financiera, las mínimas estrategias de inclusión, la nueva capacitación de sus colaboradores y la falta de trabajo articulado con otras instituciones.

\section{Contribución de la autora}

Sissy Delgado Pacheco ha participado en la concepción, la recolección de datos, la redacción y la aprobación de la versión final del artículo.

\section{Fuente de financiamiento}

Autofinanciado.

\section{Conflicto de interés}

La autora declara no tener conflictos de interés. 


\section{ANEXO}

\section{CUADRO DE ANTECEDENTES DE MUCEN Y MALI}

\begin{tabular}{|c|c|c|}
\hline $\begin{array}{l}\text { PÚBLICO } \\
\text { Número total de visitas }\end{array}$ & $\begin{array}{l}\text { MUCEN } 2018 \\
100402\end{array}$ & $\begin{array}{c}\text { MALI } 2018 \\
370000\end{array}$ \\
\hline Público nacional (\%) & $79 \%$ & $80 \%$ \\
\hline Público extranjero(\%) & $21 \%$ & $20 \%$ \\
\hline Número total de visitantes por visita educativa & 31414 & 12000 \\
\hline Recursos humanos (antes de cuarentena) & MUCEN & MALI \\
\hline $\begin{array}{l}\text { Números de empleados con especialización en Comunica- } \\
\text { ciones y Marketing }\end{array}$ & 2 & 4 \\
\hline $\begin{array}{l}\text { Número de personas dedicadas a proyectos educativos } \\
\text { (museo) }\end{array}$ & 14 & 23 \\
\hline Proceso de digitalización & MUCEN & MALI \\
\hline Google Art \& Culture & - & 2012 \\
\hline Año de inicio de digitalización de publicaciones & 2016 & 2020 \\
\hline Visitas virtuales & 2017 & - \\
\hline Banco de imágenes & 2020 & 2014 \\
\hline App, audioguías & - & 2016 \\
\hline Redes sociales & MUCEN & MALI \\
\hline Facebook & 2016 & 2008 \\
\hline YouTube & 2016 & 2012 \\
\hline Instagram & 2016 & 2016 \\
\hline Twitter & - & 2010 \\
\hline Página web & MUCEN & MALI \\
\hline Lanzamiento & 2016 & 2003 (¿?) \\
\hline
\end{tabular}

Fuente: Elaboración propia 


\section{REFERENCIAS BIBLIOGRÁFICAS}

Alemán, A. (2017). Los museos virtuales en el Perú como entornos en el proceso de construcción de la identidad cultural: caso museo virtual de gastronomía peruana (tesis de doctorado en Turismo). Universidad de San Martín de Porres, Lima. Recuperado de http://www.repositorioacademico.usmp.edu.pe/bitstream/handle/usmp/2876/ALEMAN_ CA.pdf?sequence $=1$ \&isAllowed=y

Alvarado, E. (2018). Hacia un museo sostenible: oferta y demanda de los museos y centros expositivos de Lima. Lima: Museo de Arte de Lima.

American Alliance of Museums, AAM (2020a). 4 ways museums can successfully leverage digital content and channels during Coronavirus (COVID-19). Recuperado de https://www.aam-us.org/2020/03/25/4ways-museums-can-successfully-leverage-digital-content-and-channelsduring-coronavirus-COVID-19/

American Alliance of Museums, AAM (2020b). How your museum can use social media during COVID-19. Recuperado de https://www.aam-us. org/2020/03/24/how-your-museum-can-use-social-media-during-COVID-19/

American Alliance of Museums, AAM (2020c). Curatorial dreaming in the age of COVID-19. Recuperado de https://www.aam-us.org/2020/05/04/ curatorial-dreaming-in-the-age-of-COVID-19/

Archivo Digital de Arte Peruano (2020). Archivo Digital de Arte Peruano. Recuperado de http://archi.pe/

British Council (2020). Transformando museos para el futuro. Recuperado de https://www.britishcouncil.pe/artes/cultural-skills/museos

Colbert, F. y Cuadrado, M. (2003). Marketing de las artes y de la cultura. Barcelona: Ariel.

Cóndor, J. (2019, 21 de mayo). Perú: 20\% de usuarios de audio digital ya escucha podcast. Recuperado de https://gestion.pe/tendencias/20-usuarios-audio-digital-peru-escucha-podcast-267545-noticia/

Consejo Internacional de Museos, ICOM (2020). Cómo comunicarse (¡e interactuar!) a distancia con su público. Recuperado de https://icom. museum/es/news/como-comunicarse-e-interactuar-a-distancia-con-supublico/

Davidson, H. (2020). Around 20\% of global population under coronavirus lockdown. The Guardian. Recuperado de https://www.theguardian.com/ world/2020/mar/24/nearly-20-of-global-population-under-coronaviruslockdown 
De Carli, G. (2004). Vigencia de la nueva museología en América Latina: conceptos y modelos. Revista ABRA, 24(33), pp. 55-75. Recuperado de https://www.revistas.una.ac.cr/index.php/abra/article/view/4207

Delgado, S. (2020a, 14 de mayo). Entrevista a María del Pilar Riofrío, directora del Museo Central (MUCEN).

Delgado, S. (2020b, 15 de mayo). Entrevista a Patricia Villanueva, curadora educativa (MALI).

Google Arts \& Culture (2020). Perú. Recuperado de https://artsandculture. google.com/entity/peru/m016wzw?categoryid=place

Holmquist, U. (2020). El British Council y los museos peruanos: colaboraciones para la sostenibilidad y resiliencia. Recuperado de https://pe.live.solas. britishcouncil.digital/sites/default/files/el_british_council_y_los_museos_peruanos.pdf

Ibermuseos (2020). Perú pone a disposición recorrido virtual en 3D de 12 museos. Recuperado de http://www.ibermuseos.org/recursos/noticias/ peru-pone-a-disposicion-recorrido-virtual-en-3d-de-12-museos/

Kotler, P. y Keller, K. (2012). Dirección de marketing. Ciudad de México: Pearson Educación.

Kotler, N. y Kotler, P. (2001). Estrategias y marketing de museos. Barcelona: Ariel.

Mariátegui, J. (2020, 17 de mayo). Día Internacional de los Museos: ¿Cómo se transformarán digital y culturalmente? El Comercio. Recuperado de https://elcomercio.pe/eldominical/actualidad/la-nueva-normalidadtransformacion-digital-y-cultural-en-los-museos-noticia/

Ministerio de Cultura (2012). Guía de museos del Perú. Recuperado de https://www.cultura.gob.pe/sites/default/files/paginternas/tablaarchivos/2013/09/guiamuseos191212.pdf

Ministerio de Cultura (2020). Visita virtual. Recuperado de https://visitavirtual.cultura.pe/

Museo Central (2018). Memoria. Recuperado de https://www.bcrp.gob. pe/docs/Proyeccion-Institucional/Museo/memoria-mucen-2018.pdf

Museo de Arte de Lima (2012). Museo de Arte de Lima - MALI presente en Google Art Project. Recuperado de http://www.mali.pe/not_detalle. php?id=72

Museo de Arte de Lima (2017). Fly Nasca. Recuperado de https://www. facebook.com/museodeartedelima/posts/10155624686913894/ 
Museo del Prado (2020). Casi 2 millones de usuarios visitan el Prado durante el confinamiento. Recuperado de https://www.museodelprado.es/actualidad/noticia/casi-2-millones-de-usuarios-visitan-el-prado/8a4e5d5a4006-6108-9c92-c2d9b4415101F

Organización de las Naciones Unidas para la Educación, la Ciencia y la Cultura, Unesco (2015). Recommendation concerning the Protection and Promotion of Museums and Collections, their Diversity and their Role in Society. Recuperado de https://unesdoc.unesco.org/ark:/48223/pf0000246331

Organización de las Naciones Unidas para la Educación, la Ciencia y la Cultura, Unesco (2020). Los museos ante los desafíos de COVID-19 continúan comprometidos con las comunidades. Recuperado de https://es.unesco. org/news/museos-desafios-COVID-19-continuan-comprometidos-comunidades

Repetto, L. (2020). Conversando con la ministra de Cultura. Recuperado el 7 de mayo de 2020 de https://www.facebook.com/103260157925071/ vidos/684607865674688/

Riaño, P. (2020, 13 de abril). El museo del futuro se despide de las exposiciones de masas. Recuperado de https://elpais.com/cultura/2020-04-13/ el-museo-del-futuro-se-despide-de-las-exposiciones-de-masas.html

Riofrío Flores, M. D. P., Alvarado Peña, E., Cueva Chacón, P. y Guerra Chirinos, D. (2019). Agenda de sostenibilidad para los museos y centros expositivos de Lima: ruta para su incidencia en el desarrollo sostenible de la ciudad. Lima: Museo de Arte de Lima. 